\title{
Spatial distribution characteristics of sea-ice-hazard risk in Bohai, China
}

\author{
Wei GU, ${ }^{1}$ Chengyu LIU, ${ }^{1}$ Shuai YUAN, ${ }^{2}$ Ning LI, ${ }^{1}$ Jinlong CHAO, ${ }^{1}$ Lantao LI, ${ }^{1}$ \\ Yingjun $X U^{1}$ \\ ${ }^{1}$ State Key Laboratory of Earth Surface Processes and Resource Ecology, Beijing Normal University, Beijing, China \\ E-mail: liuchengyugis@qq.com \\ ${ }^{2}$ National Marine Environment Monitoring Center, Dalian, China
}

\begin{abstract}
Sea-ice hazard causes serious harm to aquaculture, marine navigation, offshore oil production and other activities in the Bohai Sea, China. To study the spatial distribution characteristics of sea-ice-hazard risk in Bohai is therefore desirable. The thickness and area of sea ice in the Bohai Sea during the winters (December-March) of 1987-2011 were estimated using data from the NOAA (US National Oceanic and Atmospheric Administration) satellite. The sea-ice thickness was converted into a sea-ice-hazard index after defining this index, and the different sea-ice-hazard risk grades were classified. The occurrence probability of sea-ice hazard was also calculated using fuzzy risk theory, and the spatial distribution characteristics of sea-ice-hazard risk in the Bohai Sea were studied. The results show that the sea-ice-hazard risk for offshore aquaculture decreased as the offshore distance increased. All the oilfields in Liaodong Bay are influenced by sea-ice hazard, two of the fields in Bohai Bay are slightly affected and the remaining fields are not influenced. The risk for marine navigation is related to the location of the port and the distance from the port. The risk in the port area is the highest; it is reduced by more than $30 \%$ at distances $10 \mathrm{~km}$ away from the port.
\end{abstract}

\section{INTRODUCTION}

Bohai is an inland sea of China, located at $37^{\circ} 07^{\prime}$ $41^{\circ} 00^{\prime} \mathrm{N}, 117^{\circ} 35^{\prime}-121^{\circ} 10^{\prime} \mathrm{E}$. It can be divided into Liaodong Bay, Bohai Bay, Laizhou Bay and the Central Bohai Sea.

The Bohai marine industry is very well developed, including marine fishery, marine transportation, sea-salt industry, offshore oil industry, coastal tourism industry, etc. In 2010, the gross ocean production in the Bohai Rim reached about 0.19 trillion dollars, accounting for $34.5 \%$ of the countrywide gross ocean production (SOAPRC, 2011a).

Sea ice is a major marine hazard in the winter in the Bohai region. It has caused serious harm to marine industries by blockading ports, blocking waterways, damaging vessels, destroying marine structures, knocking down offshore oil platforms and reducing the aquaculture yield. A 30-yearfrequency severe sea-ice hazard occurred in the Bohai region in the winter of 2009/10; 61000 people suffered damage, and the direct economic loss reached 0.93 billion dollars (SOAPRC, 2011b).

Since 1980, Chinese scholars have been studying the seaice hazard in Bohai. They have focused on the characteristics of sea-ice hazard (Deng, 1986), related countermeasures (Lu, 1993), the harm caused to harbor and marine facilities by sea ice (Fu and others, 2007), the impact on navigation (Zhang and Zhou, 2003), sea-ice hazards in relation to aquaculture (Xue and others, 2004; Xu and others, 2010) and other similar aspects. These studies focused on the mechanism of sea-ice hazard in the Bohai region and rarely dealt with sea-ice-hazard risk and its distribution characteristics. International research on sea-ice hazard is mainly concerned with the security of shipping and maritime operations in the Arctic and the high-latitude areas (Atlantic, Pacific) (Whiteman, 2011; Eicken and others, 2011). The best-known example of a sea-ice hazard is the
Titanic event of 14 April 1912, which caused 1523 deaths. To prevent or mitigate the influence of sea-ice hazard on marine transportation and other maritime exercises, the Disaster Management Support Group (DMSG), which was set up by the Committee on Earth Observation Satellites (CEOS), carried out research on the monitoring and forecasting of sea ice based on remote-sensing technology.

This study used data from the NOAA (US National Oceanic and Atmospheric Administration) satellite on the freezing occurrences at Bohai during the winters (December-March) of 1987-2011, based on inversion processing of remote-sensing data and GIS technology, and derived the spatial distribution and the temporal variations of the sequence data related to sea-ice thickness in Bohai. On this basis, according to the damaging effects of sea ice on aquaculture, marine transportation and offshore oil plants, three types of sea-ice-hazard risk were calculated and their spatial distributions were evaluated, with the aim of providing a reference for work on prevention of sea-ice hazard in the Bohai region.

\section{DATA AND METHODS}

\subsection{Data source}

Hazard-risk research needs to be based on a large number of sample data, so a detailed time sequence of data on the area and thickness of sea ice is an important database for studies on sea-ice-hazard risk. We used satellite remote-sensing data to obtain the time-series details of the area and thickness of sea ice in the Bohai region. The satellite remote-sensing data were obtained from the University of Tokyo's NOAA database in Japan and the Chinese National Satellite Meteorological Center (NSMC). The image coverage area was $36-42^{\circ} \mathrm{N}, 116-124^{\circ} \mathrm{E}$. Among more than 2000 images obtained during the winters (December-March) of the period 


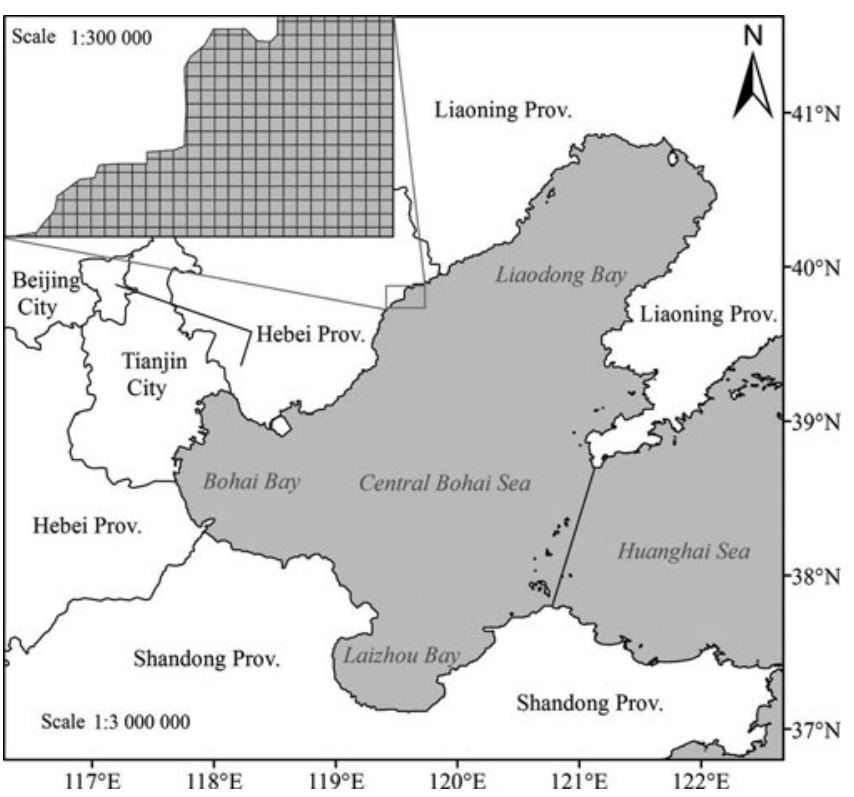

Fig. 1. Schematic map of the geographical grid in the Bohai Sea.

1987-2011, those covered by clouds or of inferior quality were removed; 580 satellite images were finally selected, and information regarding the iced area and the thickness of sea ice was extracted from these images.

\subsection{Data processing}

Extraction of information regarding sea-ice area was mainly based on differences in the reflectance of sea ice, sea water and land, which were obtained by the NOAA satellite images of the second and fourth bands, to identify the icewater separation (Xie and others, 2006; Guo and others, 2008) and to determine the distribution range of sea ice. The impact of silt, brought in by rivers from the Bohai coastal area, on sea-water reflectivity was considered, and the icewater reflectance threshold for the different sea areas was then determined. Finally, values were extracted for the seaice area according to the threshold. The error in the determination of the sea-ice area was about $10 \%$ (Xie and others, 2003).

The extraction of information on sea-ice thickness was mainly based on the correlation between sea-ice thickness and reflectance (Xie and others, 2003). Based on shortwave radiation theory, the inversion model for sea-ice thickness is

$$
\alpha(h)=\alpha_{\max }(1-\kappa \exp (-\mu h)]
$$

where $h$ is the sea-ice thickness, $\alpha(h)$ is the reflectance of the solar radiation spectrum from sea ice, which changes with the ice thickness, $\alpha_{\max }$ is the reflectance of ice of infinite thickness, $\mu$ is the attenuation coefficient for the reflectance and $\kappa$ is a related coefficient associated with $\alpha_{\text {max }}$ and $\alpha_{\text {sea }}$ (Yuan and others, 2012). The parameters in Eqn (1) are determined according to the actual occurrence of the sea ice in different areas of the Bohai region, and the thickness inversion for sea ice in different areas was calculated based on Eqn (1). The error in thickness inversion in Bohai was 1525\% (Yuan and others, 2012).

To quantitatively reflect the spatial distribution features of sea-ice-hazard risk in the Bohai area, a $1 \times 1 \mathrm{~km}^{2}$ grid was used as the basic unit of division, and the Bohai area was differentiated into 73944 geographic gridpoints. The
Table 1. Ice-thickness-limit indexes of different hazard-bearing bodies and the grades of ice hazard

Type of hazard-bearing body Ice-thickness-limit index

$h_{1} \quad h_{2}$

$\mathrm{cm}$ $\mathrm{cm}$

Offshore aquaculture

Marine transportation

Offshore oil engineering

$\begin{array}{cc}5 & 15 \\ 15 & 25\end{array}$

Interactive Data Language program was used to calculate the ice thickness in each unit of the 580 satellite remotesensing images. The results constitute the database for calculating sea-ice-hazard risk in each grid, with the total sample number amounting to 42887520 .

\subsection{Definition of sea-ice-hazard index}

For different hazard-bearing bodies, whether the sea ice can cause hazard or not mainly depends on the ice thickness. According to the Ice Forecasting Level, Sea-ice-hazard Emergency Plan, Sea-ice-hazard Bulletin, and other related documents from the State Oceanic Adminstration People's Republic of China (SOAPRC), and in the context of results from related research on the damage to offshore aquaculture, marine transportation and offshore oil engineering caused by sea ice, the sea-ice hazard in the Bohai Sea was divided into three grades in this study: no hazard, mild hazard and severe hazard (Zhang and Zhou, 2003; Li and others, 2004; Hu and others, 2009; Cheng and others, 2011). Three grades of sea-ice hazard corresponding to the ice-thickness-limit indexes $h_{1}$ and $h_{2}$ (Table 1 ) were assigned to the three types of hazard-bearing bodies: offshore aquaculture, marine transportation and offshore oil engineering. The index $h_{1}$ is the sea-ice-thickness limit under mild-grade sea-ice hazard, and $h_{2}$ is the thickness limit for a severe level of sea-ice hazard, such that the interval $0-h_{1}$ represents the no-hazard zone, $h_{1}-h_{2}$ comprises mild hazard, and a value $>h_{2}$ represents severe hazard. Through a comparison of the values of $h, h_{1}$ and $h_{2}$, the degree of seaice hazard can be judged for an area with ice thickness $h$.

The range of sea-ice thickness $h$ changes with the ice situation grade, and there is a great difference between the grades. For floating sea ice, the ice thickness is approximately $0-15 \mathrm{~cm}$ in a light ice year, $0-30 \mathrm{~cm}$ in a normal ice year and $0-50 \mathrm{~cm}$ for a heavy ice year. Generally, the ice thickness can reach $30-100 \mathrm{~cm}$, sometimes even $>200 \mathrm{~cm}$ for landfast ice in coastal areas. Obviously, the differences in the magnitude of ice thickness can be inconvenient for the calculation of sea-ice-hazard risk, and hence it needs to be normalized. Therefore, we define the sea-ice-hazard index to quantitatively describe the severity of the sea-ice hazard and to analyze the distribution of sea-ice-hazard risk by calculating the probability of the sea-ice-hazard index in the entire Bohai area.

The sea-ice-hazard index is a piecewise monotonic increasing function, which is related to the ice thickness $h$, and its value is in the interval $(0,1)$. The sea-ice-hazard index can be divided into three sections corresponding to the three grades of sea-ice hazard, namely $\left(0, d_{1}\right),\left(d_{1}, d_{2}\right)$, $\left(d_{2}, 1\right)$, where $d_{1}=1 / 3$ and $d_{2}=2 / 3$. The expression for the 
sea-ice-hazard index $G(h)$ is

$$
G(h)=\left\{\begin{array}{cc}
\frac{d_{1}}{h_{1}} & h \in\left(0, h_{1}\right) \\
\frac{\left(h-h_{1}\right) d_{2}+\left(h_{2}-h\right) d_{1}}{h_{2}-h_{1}} & h \in\left(h_{1}, h_{2}\right) \\
1-\left(1-d_{2}\right)^{\frac{h}{h_{2}}} & h \in\left[h_{2},+\infty\right)
\end{array}\right.
$$

Combining Eqn (2) and Table 1, specific expressions can be obtained for the sea-ice-hazard index $G^{(1)}(x, y, h)$ for offshore aquaculture, $G^{(2)}(x, y, h)$ for marine transportation and $G^{(3)}(x, y, h)$ for offshore oil engineering, respectively, as follows:

$$
G^{(1)}(x, y, h)=\left\{\begin{array}{cc}
\frac{h(x, y)}{15} & h(x, y) \in(0,5) \\
\frac{h(x, y)+5}{30} & h(x, y) \in(5,15) \\
1 & -3^{-\frac{h(x, y)}{15}} h(x, y) \in(15,+\infty)
\end{array}\right.
$$

$$
\begin{gathered}
G^{(2)}(x, y, h)=\left\{\begin{array}{cc}
\frac{h(x, y)}{45} & h(x, y) \in(0,15) \\
\frac{h(x, y)-5}{30} & h(x, y) \in(15,25) \\
1-3^{-\frac{h(x, y)}{25}} & h(x, y) \in(25,+\infty)
\end{array}\right. \\
G^{(3)}(x, y, h)=\left\{\begin{array}{cc}
\frac{h(x, y)}{75} & h(x, y) \in(0,25) \\
\frac{h(x, y)-10}{45} & h(x, y) \in(25,40) \\
1-3^{-\frac{h(x, y)}{40}} & h(x, y) \in(40,+\infty)
\end{array}\right.
\end{gathered}
$$

where $x$ and $y$ indicate the map coordinates of arbitrary gridpoints in Figure 1, $x$ for the east-west direction, and $y$ for the north-south direction; $h(x, y)$ is the sea-ice thickness of each gridpoint. Figure 2 illustrates the distribution curves of the three functions $G^{(1)}, G^{(2)}$ and $G^{(3)}$. As can be seen from the graph, all of these are piecewise monotonic increasing functions, with values in the interval $(0,1)$.

In fact, the relationship between the sea-ice thickness and sea-ice-hazard index may be more complex, not just a linear or an exponential function. However, there are not adequate data of the losses caused by sea-ice hazard over a long period, and the interaction of sea ice with a hazard-bearing body is also complicated. The function $G$ was determined based on both the authors' experience and subjective awareness.

\subsection{Methods of calculating sea-ice-hazard risk}

Owing to restricted access to satellite data, the gridpoints of the sea-ice thickness samples (580) during winter (December-March) for the period 1987-2011 were not continuously and evenly distributed. We used a fuzzy risk theory method to calculate the probability of sea-ice-hazard occurrence.

The parameter $h(x, y)$, corresponding to the 580 values of sea-ice thickness for each gridpoint during the winters of 1987-2011, constitutes the independent sample set $A_{x, y}$ for the sea-ice thickness for each grid, with $h(x, y) \in A_{x, y}$ The three types of sea-ice-hazard indexes, $G^{(1)}(x, y, h)$, $G^{(2)}(x, y, h)$ and $G^{(3)}(x, y, h)$, for each grid can be calculated using Eqns (3a), (3b) and (3c), and these indexes constitute a sample set of three new and independent seaice-hazard indexes, denoted by $D_{x, y}^{(1)} D_{x, y}^{(2)}$ and $D_{x, y}^{(3)}$, respectively, with $G^{(1)}(x, y, h) \in D_{x, y}^{(1)}, G^{(2)}(x, y, h) \in D_{x, y}^{(2)}$ and $G^{(3)}(x, y, h) \in D_{x, y}^{(3)}$. In this case, the grade of sea-ice

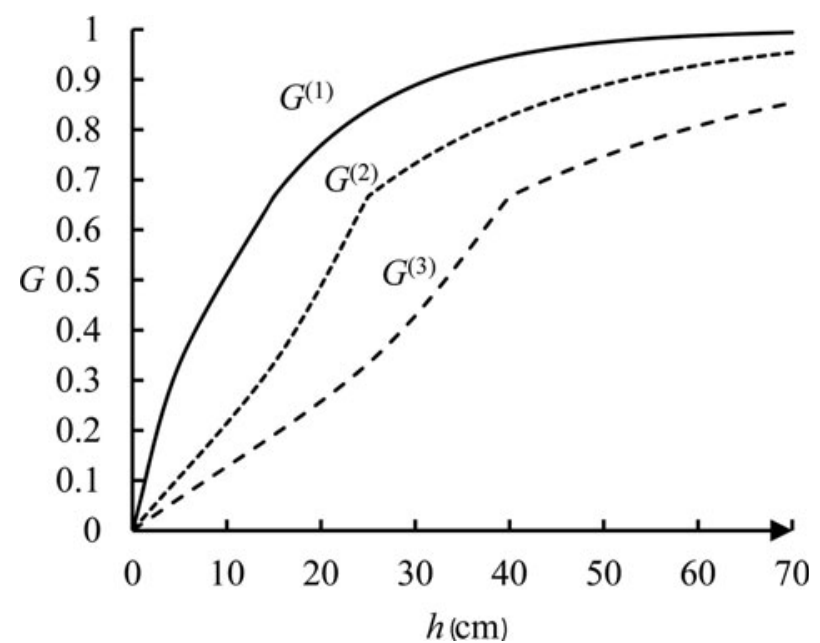

Fig. 2. The curves of functions $G^{(1)}, G^{(2)}$ and $G^{(3)}$.

hazard, as indicated by the sea-ice thickness, can be converted to indicate the sea-ice-hazard index. In other words, when the range of values of $G^{(1)}(x, y, h), G^{(2)}(x, y, h)$ and $G^{(3)}(x, y, h)$ was in the interval $(0,1 / 3)$, it indicated that there were no hazards; a range in $(1 / 3,2 / 3)$ indicated a mild hazard; and a range in $(2 / 3,1)$ indicated a severe hazard. The value of the sea-ice-hazard index can reflect the degree of sea-ice hazard.

The midpoints of the intervals $(0,1 / 3),(1 / 3,2 / 3)$ and $(2 / 3,1)$ formed a basic discrete domain for the three types of sea-ice-hazard indexes. The domain for each grid is $U^{(k)}(x, y)=\left\{u_{j k}(x, y) \mid j=1,2,3\right\}$, where $u_{1 k}(x, y)=1 / 6$, $u_{2 k}(x, y)=1 / 2, u_{3 k}(x, y)=5 / 6$; with $k=1,2,3$ representing the types of sea-ice hazard (1: sea-ice hazard for offshore aquaculture; 2: sea-ice hazard for marine transportation; 3: sea-ice hazard for offshore oil engineering). Here $j$ is the interval number, where $j=1$ corresponds to the interval $(0$, $1 / 3), j=2$ corresponds to the interval $(1 / 3,2 / 3)$ and $j=3$ corresponds to the interval $(2 / 3,1)$.

For each gridpoint $(x, y)$, the basic discrete domain $U^{(k)}(x$, $y$ ) of every type of sea-ice-hazard index satisfies the following interval theorem:

$$
I^{(k)}(x, y)=\left\{l_{j}^{k}(x, y) \mid j=1,2,3\right\}
$$

where $I_{1}^{k}(x, y)=\left(0, \frac{1}{3}\right), I_{2}^{k}(x, y)=\left(\frac{1}{3}, \frac{2}{3}\right)$, and $I_{3}^{k}(x, y)=\left(\frac{2}{3}, 1\right)$. For $G^{(k)}(x, y, h) \in D_{x, y}^{(k)}$, the collection consisting of $G^{(k)}(x, y, h) \in l_{j}^{k}(x, y)$ is called the interior set of $l_{j}^{k}(x, y)$, and the collection consisting of $G^{(k)}(x, y, h) \notin l_{j}^{k}(x, y)$ is known as the outer set of $l_{j}^{k}(x, y)$.

The information distributions for sample sets $D_{x, y}^{(1)}, D_{x, y}^{(2)}$ and $D_{x, y}^{(3)}$ were evaluated using a one-dimensional linear information distribution method (Huang, 2006); the calculation equation is

$$
\begin{gathered}
q_{j}^{(k)}(x, y, h)= \\
\left\{\begin{array}{cc}
1-\frac{\left|G^{(k)}(x, y, h)-u_{j k}(x, y)\right|}{\Delta} & \left|G^{(k)}(x, y, h)-u_{j k}(x, y)\right| \leq \Delta, \\
& G^{(k)}(x, y, h) \in\left(u_{j k}(x, y)-\frac{1}{6}, u_{j k}(x, y)+\frac{1}{6}\right) \\
0 & \text { otherwise }
\end{array}\right.
\end{gathered}
$$

where $j=1,2,3$ and $\Delta=1 / 3$ is the length of the interval. 

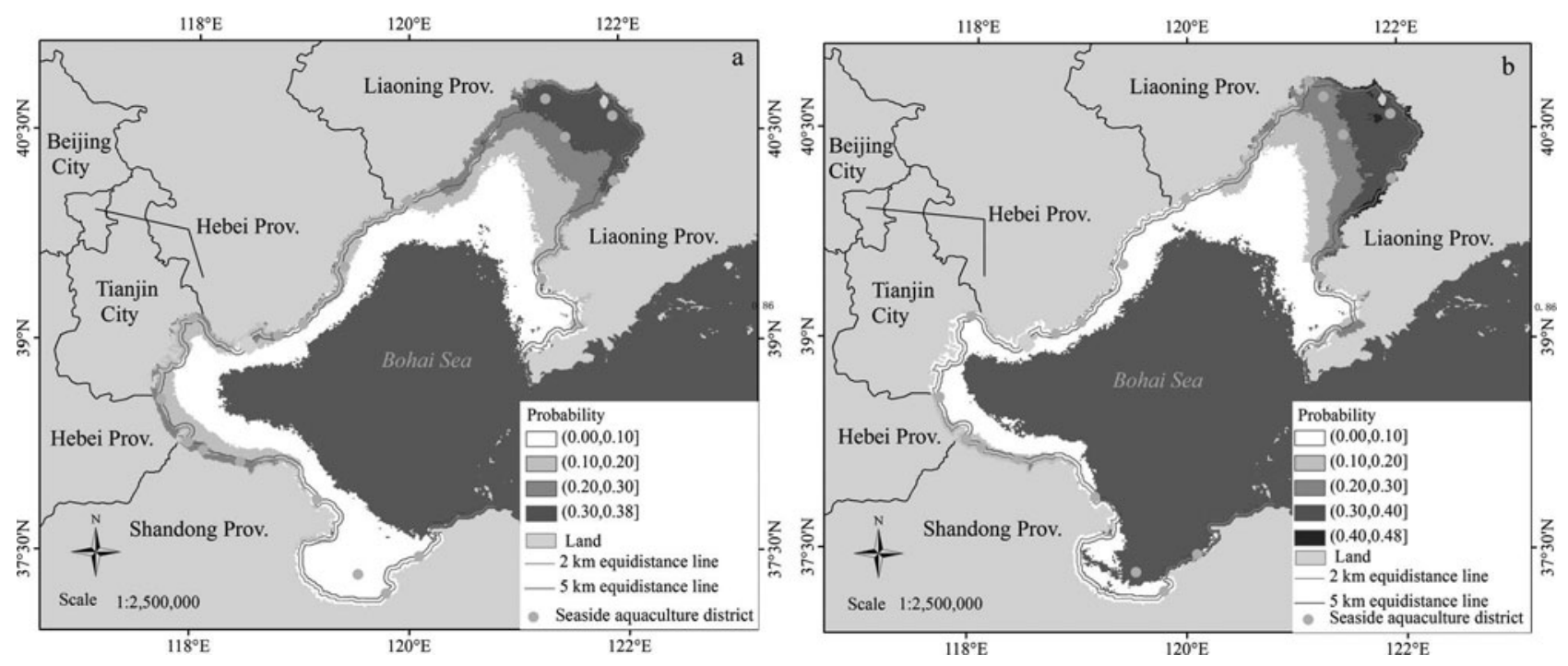

Fig. 3. Spatial distribution map of the average probabilities of sea-ice hazard for offshore aquaculture in Bohai Sea. (a) Mild hazard. (b) Severe hazard.

There are 580 data related to sea-ice thickness in each grid, and the probability domain of the three types of seaice-hazard index is

$$
P^{(k)}(x, y)=\left\{0, \frac{1}{580}, \frac{2}{580}, \ldots, 1\right\}
$$

The possibility-probability distribution of sea-ice hazard, $\pi_{l_{j}^{k}(x, y)}^{(k)}\left(x, y, \xi_{i}^{k}\right)$, was calculated for offshore aquaculture, marine transportation and offshore oil engineering, by using the interior-outer-set model. Here $\xi_{i}^{k}$ is a corresponding probability, where $\xi_{i}^{k} \in P^{(k)}(x, y)$ (Huang, 2002; Huang and Shi, 2002). The average probability of each type of sea-ice hazard was used to measure the risk of every corresponding hazard.

The average probability $c\left(x, y, l_{j}^{k}\right)$ was then calculated for the intervals indicating different grades of offshore aquaculture, marine transportation and offshore oil engineering sea-ice-hazard indexes (Zadeh, 1968). The calculation expression is

$$
c\left(x, y, l_{j}^{k}\right)=\frac{\sum_{i=0}^{N} \xi_{i}^{k} \pi_{l_{j}^{k}(x, y)}^{(k)}\left(x, y, \xi_{i}^{k}\right)}{\sum_{i=0}^{N} \pi_{l_{j}^{k}(x, y)}^{(k)}\left(x, y, \xi_{i}^{k}\right)} \quad(j=1,2,3 ; k=1,2,3)
$$

The equation for the normalized probability is

$$
p^{(k)}\left(x, y, l_{i}^{k}\right)=\frac{c\left(x, y, l_{i}^{k}\right)}{\sum_{j=1}^{3} c\left(x, y, l_{j}^{k}\right)}(i=1,2,3 ; k=1,2,3)
$$

Equation (8) is used to calculate the probability of occurrence of sea-ice hazard. Its corresponding relations for the different hazard-bearing bodies and their different grades of sea-ice hazard are shown in Table 2.

\section{RESULTS AND ANALYSIS}

Using the calculation methods described in Sections 2.3 and 2.4 to compute the three types of sea-ice-hazard indexes and the occurrence probabilities of the hazard of every grid illustrated in Figure 1, the spatial distribution maps of the occurrence probability for the three types of sea-ice hazards were drawn to analyze the distribution characteristics of seaice hazard in Bohai.

\subsection{Distribution characteristics of sea-ice-hazard risk for offshore aquaculture}

The major offshore aquaculture status and the distribution of sea-ice-hazard risk are illustrated in Figure 3. The main area of the Bohai is in the offshore range within a $2 \mathrm{~km}$ equidistance area, where the average probabilities of mild sea-ice hazard for offshore aquaculture are as follows: Liaodong Bay $>0.3000$, Bohai Bay $>0.2000$, Laizhou Bay $>0.1000$. In the $2-5 \mathrm{~km}$ offshore equidistance area range, the average probabilities of mild sea-ice hazard for offshore aquaculture are Liaodong Bay $>0.2000$, Bohai Bay $>0.1000$ and Laizhou Bay $>0.0500$ (Fig. 3a). In the $2 \mathrm{~km}$ offshore equidistance area range, the average probabilities of severe sea-ice hazard for offshore aquaculture are Liaodong Bay $>0.2000$, Bohai Bay and Laizhou Bay $>0.0300$. In the $2-5 \mathrm{~km}$ offshore equidistance area range, the average probabilities of severe sea-ice hazard for offshore aquaculture are Liaodong Bay $>0.1000$, Bohai Bay and Laizhou Bay $>0.0100$ (Fig. 3b).

Table 2. The occurrence probability of the different grades of seaice hazard for different hazard-bearings

\begin{tabular}{lc} 
Expression & Description of hazard probability \\
\hline$p^{(1)}\left(x, y, l_{2}^{1}\right)$ & $\begin{array}{c}\text { Probability of mild sea-ice hazard for } \\
\text { offshore aquaculture }\end{array}$ \\
$p^{(1)}\left(x, y, l_{3}^{1}\right)$ & $\begin{array}{c}\text { Probability of severe sea-ice hazard for } \\
\text { offshore aquaculture }\end{array}$ \\
$p^{(2)}\left(x, y, l_{2}^{2}\right)$ & $\begin{array}{c}\text { Probability of mild sea-ice hazard for } \\
\text { marine transportation }\end{array}$ \\
$p^{(2)}\left(x, y, l_{3}^{2}\right)$ & $\begin{array}{c}\text { Probability of severe sea-ice hazard for } \\
\text { marine transportation }\end{array}$ \\
$p^{(3)}\left(x, y, l_{2}^{3}\right)$ & $\begin{array}{c}\text { Probability of mild sea-ice hazard for } \\
\text { offshore oil engineering }\end{array}$ \\
$p^{(3)}\left(x, y, l_{3}^{3}\right)$ & $\begin{array}{c}\text { Probability of severe sea-ice hazard for } \\
\text { offshore oil engineering }\end{array}$
\end{tabular}



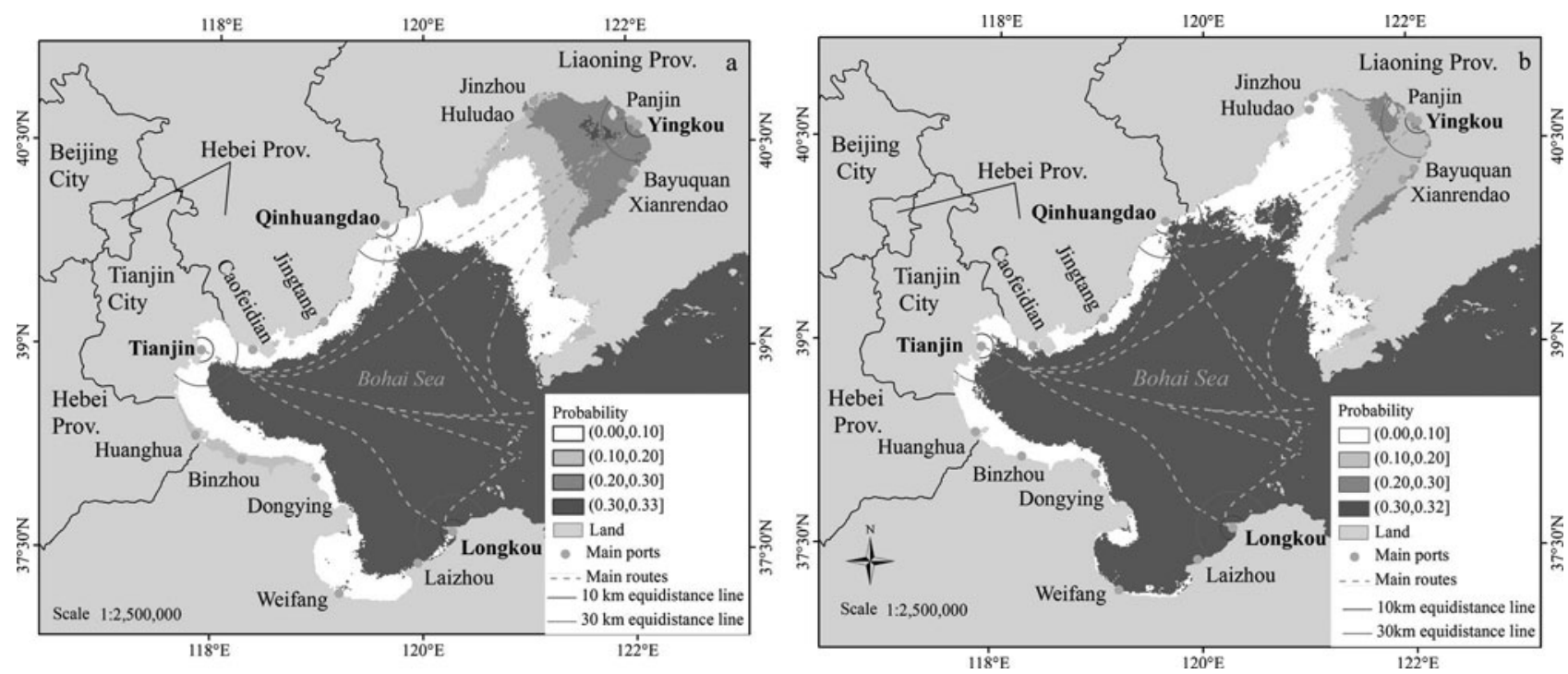

Fig. 4. Spatial distribution map of the average probabilities of sea-ice hazard for marine transportation. (a) Mild hazard. (b) Severe hazard.

Liaodong Bay is the area with high risk of sea-ice hazard for offshore aquaculture, with the maximum probabilities of mild and severe sea-ice hazard being 0.3800 and 0.4800 , respectively; therefore, it is not suitable for large-scale development of offshore aquaculture. There was a severe sea-ice hazard in Liaodong Bay in winter 2009/10, with the loss of offshore aquaculture costing 0.50 billion dollars. The losses in Bohai and Laizhou Bays amounted to 0.38 billion dollars. Although the sea-ice-hazard risk in Bohai and Laizhou Bays is lower than that in Liaodong Bay, this does not mean that there will be no severe offshore aquaculture sea-ice hazards in the region (average probability $>0$ ); this is because the offshore aquaculture plants are mainly located in this area and if a severe ice hazard occurs, it can cause serious losses.

\subsection{Distribution characteristics of sea-ice-hazard risk for marine transportation}

The main sea routes and sea-ice-hazard risk distribution in Bohai are illustrated in Figure 4. Although there are many ports along the Bohai coast, the ports that are related to the main route are Yingkou, Qinghuangdao, Tianjin and Longkou. The occurrence probability of sea-ice hazard in the four ports is shown in Figure 5. From Figure 4, it can be seen that Yingkou port is at the greatest risk, with occurrence probability of mild hazard of 0.2690 and a severe hazard probability of 0.2067 . The sea-ice-hazard risk in Qinghuangdao and Tianjin ports is lower, with the occurrence probability of mild hazard being $0.0413-0.0463$ and that of severe hazard being 0.0096-0.0149. The sea-ice-hazard risk in Longkou port is the lowest, with the mild hazard occurrence probability being 0.0012 and that of severe hazard being zero.

From Figure 4, it can be seen the average probability of sea-ice hazard changes sigificantly with distance from the port. To quantitatively reflect this diversity, we considered Yingkou, Qinghuangdao, Tianjin and Longkou ports as the starting points and evaluated the average probability of both mild and severe sea-ice hazards in relation to distance from the port within the $0-30 \mathrm{~km}$ range of the four ports (Fig. 5).

In the context of mild sea-ice hazard for marine transportation, the average probability of hazard is 0.2400
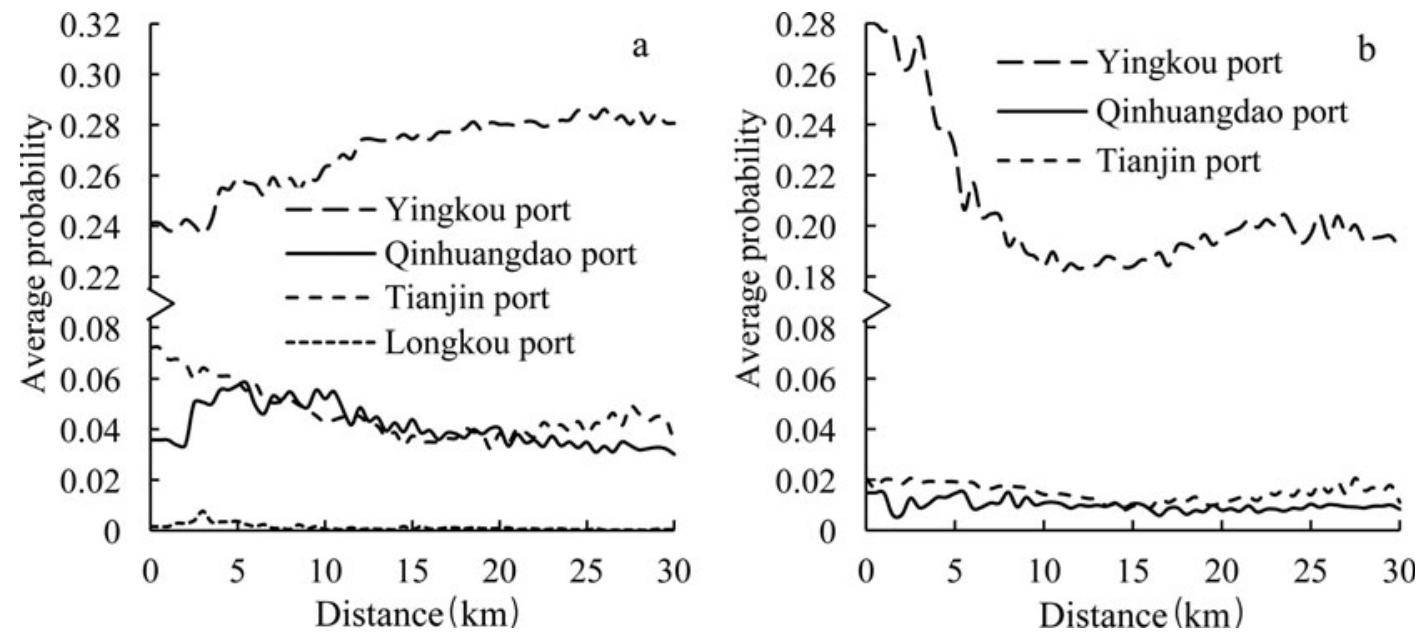

Fig. 5. The variation in the average probabilities of sea-ice hazard with different distances from the ports of the four main route lines. (a) Mild hazard. (b) Severe hazard. 

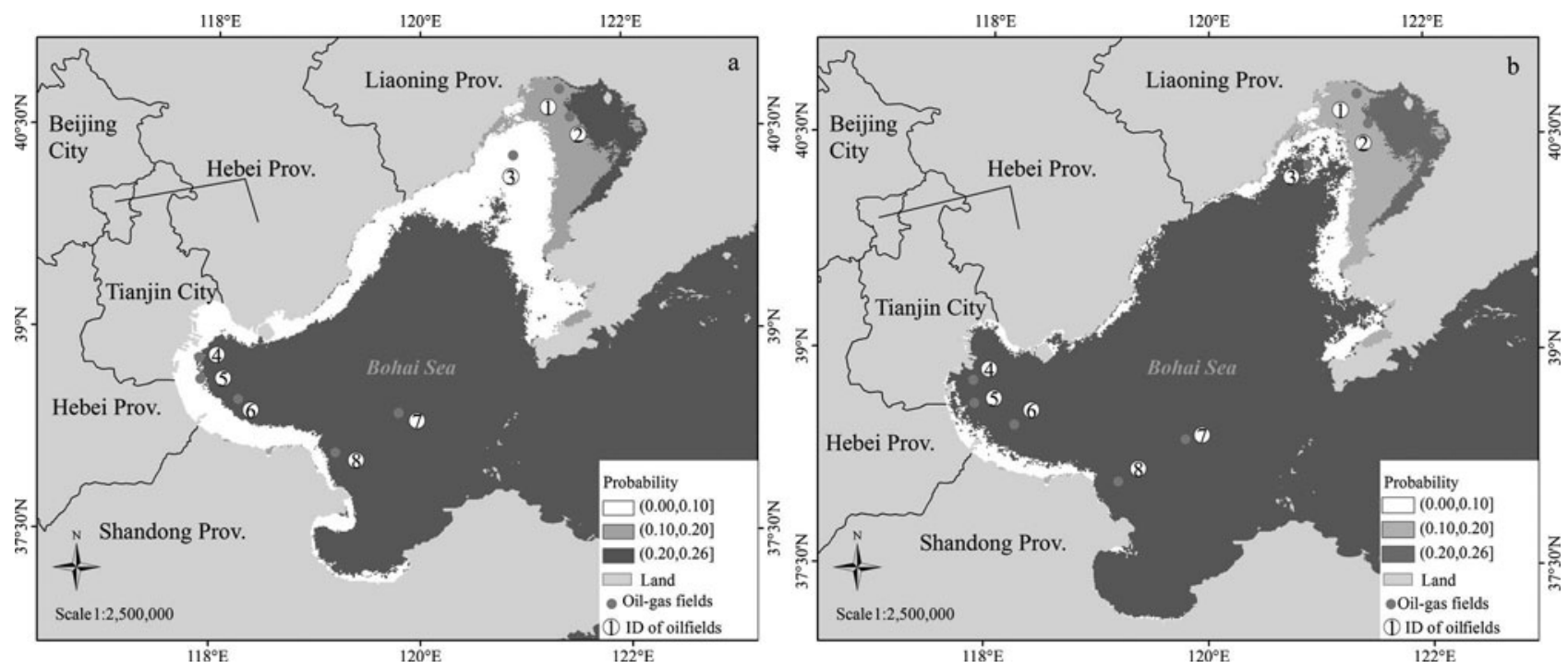

Fig. 6. The distribution characteristics of sea-ice hazard for offshore oil engineering. (a) Mild hazard. (b) Severe hazard.

within the $0-30 \mathrm{~km}$ range of Yingkou port, that for Qinghuangdao and Tianjin ports varies in the vicinity of 0.0500 in the $0-30 \mathrm{~km}$ range, and the average probability is close to zero for Longkou port over the same range.

Similarly, for severe sea-ice hazard to marine transportation, the average probability reduced sharply from 0.2800 to 0.1800 over the $0-10 \mathrm{~km}$ range of Yingkou port, a $36 \%$ reduction; the average probability is around $0.1700-0.1900$ in the $10-30 \mathrm{~km}$ range, an $11.8 \%$ reduction. For Qinghuangdao port, the average probability reduced from 0.0140 to 0.0100 over the $0-10 \mathrm{~km}$ range, a $29 \%$ reduction, and the average probability is approximately $0.0050-0.1100$ in the $10-30 \mathrm{~km}$ range. For Tianjin port the average probability reduced from 0.0210 to 0.0150 over the $0-10 \mathrm{~km}$ range, a $25 \%$ reduction, with the value being around $0.0080-0.0200$ in the $10-30 \mathrm{~km}$ range. For Longkou port, the severe-hazard probability in the $0-30 \mathrm{~km}$ range is zero. Therefore, in terms of the magnitude of sea-ice-hazard probability, the order is Yingkou port > Tianjin port > Qinghuangdao port > Longkou port.

\subsection{Distribution characteristics of sea-ice-hazard risk for offshore oil engineering}

The major oilfields and the distribution of sea-ice-hazard risk are presented in Figure 6 . As can be seen, all the oilfields in Liaodong Bay (Nos. 1-3) are influenced by sea-ice hazard; the average probability of mild sea-ice hazard is 0.1320 , and that for a severe hazard is 0.1310 . Two oilfields (Nos. 4 and 5) in Bohai Bay are influenced by mild sea-ice hazard, with average probability values of 0.0169 and 0.0175 , respectively. The oilfields numbered 6, 7 and 8, in Bohai Bay, Laizhou Bay and the Central Bohai Sea, respectively, are free of the influence of sea-ice hazard.

\section{DISCUSSION}

Because monitoring the sea ice and its hazard is complicated and dangerous work, completing the work requires advanced detection methods and a high level of technology. Because of various restrictions, authoritative detailed data of sea ice and its hazard in the Bohai region have not yet been obtained. In this study, the data on sea-ice thickness retrieved from satellite remote-sensing images have been used to analyze the risk of sea-ice hazard. This is just an initial endeavor, because sea-ice thickness is not the only factor controlling sea-ice hazard. Based on the ice thickness and strength, Li and others (2004) have set up a new division of ice engineering sub-areas that is very reasonable and useful. But it is difficult to acquire information such as the sea-ice structure of the vast extent of sea area in the Bohai Sea using remote-sensing technology, especially the high-resolution data of sea-ice structure information synchronized with the ice thickness retrieved based on remote-sensing images. In order to make clear the spatial characteristics of sea-icehazard distribution, only the ice thickness was selected to calculate the sea-ice-hazard index, and the estimation of a sea-ice-hazard index with more sea-ice parameters is also our future work based on remote-sensing technology.

The local governments in the Bohai coastal area do not have detailed statistical records of losses caused by sea-ice hazard over a long period. The only record available is the data on loss due to sea-ice hazard in Bohai for the year 2009/10 published in the China Marine Calamities Bulletin. This study is mainly focused on the occurrence probability, and owing to this lack of previous statistics, a thorough analysis of the loss situation is difficult. The relationship between sea-ice thickness and the grades of sea-ice hazard, and the grades and classification of sea-ice hazard, obtained in this paper largely depend on the authors' experience and subjective awareness. There may be other ways of calculating these. It is also necessary to carry out more objectively and quantitatively extensive field investigations and experiments on the hazard mechanism to establish the sea-icehazard model and the classification graduation system for sea-ice hazard.

\section{CONCLUSIONS}

The area and thickness of sea ice were retrieved from NOAA remote-sensing images using the zonal threshold method and the ice-thickness inversion model based on shortwave radiation theory. The sea-ice hazard was calculated for different types and grades of sea-ice hazard using the icethickness and sea-ice-hazard model, and the probability of 
the occurrence of those sea-ice hazards was also estimated. From the maps of sea-ice-hazard risk, we conclude that:

1. The sea-ice-hazard index is an important parameter. Given the lack of effective data on sea-ice-hazard losses in the long term and the investigation between the sea ice and the hazard-bearing body, the index had to be determined according to the authors' experience and subjective awareness. But it still reflects the relationship between sea-ice hazard and ice thickness to some degree.

2. The risk of sea-ice hazard to offshore aquaculture reduced gradually with increasing distance from the shore: the greatest risk is in the $0-2 \mathrm{~km}$ range; the risk reduced by nearly half in the $2-5 \mathrm{~km}$ range (Bohai and Laizhou Bays).

3. The sea-ice-hazard risk for marine transportation is related to the location of and the distance from the port. In a harbor district with the largest sea-ice-hazard risk, the risk is reduced by more than $30 \%$ in the area that is $10 \mathrm{~km}$ away from the port.

4. All oilfields in the Bohai region are influenced by sea-ice hazard; the average probability of mild hazard is 0.1320 , and the probability of severe hazard is 0.1310 . The other oilfields are free of the influence of sea-ice-hazard risk.

\section{ACKNOWLEDGEMENTS}

This study was supported by the following Chinese government science and technology projects: National Basic Research Program of China (973 Program) (No. 2012CB955402); National High Technology Research and Development Program of China (No. 2011AA100505); Project supported by State Key Laboratory of Earth Surface Processes and Resources Ecology of China (2011-TDZD050); Natural Science Foundation of China (No. 40801230).

\section{REFERENCES}

Cheng H, Liu D and Gao Z (2011) Discussion on sea ice disaster to the oil and gas facilities of shallow sea and its reduction measures. J. Liaoning Shihua Univ., 31(1), 32-39 [in Chinese]

Deng S (1986) Sea ice disaster in Bohai Sea and the general situation of its prevention. J. Catastroph., 1, 80 [in Chinese]

Eicken $\mathrm{H}$ and 6 others (2011) Environmental security in Arctic icecovered seas: from strategy to tactics of hazard identification and emergency response. Mar. Technol. Soc. J., 45(3), 37-48 (doi: 10.4031/MTSJ.45.3.1)
Fu B, Song X, Guo Z and Ning S (2007) Impact of sea ice on harbor operation and countermeasures. J. Waterway Harbor, 28(6), 444-447 [in Chinese]

Guo Q, Gu W, Sun C, Jin H and Li J (2008) Study on the revised model for extraction of sea-ice area in the Bohai Sea based on remote-sensing data. Mar. Sci., 32(8), 70-75 [in Chinese]

Hu Z, Chen W, Tang M and Liu Q (2009) Analysis of sea ice compressive strength characters in the east shore of Liaodong Bay. Mar. Forecasts, 26(4), 11-18 [in Chinese]

Huang C (2002) An application of calculated fuzzy risk. Inform. Sci., 142(1-4), 37-56 (doi: 10.1016/S0020-0255(02)00156-1)

Huang C (2006) Risk assessment of natural disaster (theory and practice). Science Press of China, Beijing

Huang C and Shi Y (2002) Towards efficient fuzzy information processing: using the principle of information diffusion. (Studies in Fuzziness and Soft Computing 99) Springer, Berlin

Li Z-J, Lu P and Sodhi DS (2004) Ice engineering sub-areas in Bohai from ice physical and mechanical parameters. Adv. Water Sci., 15(5), 598-602 [in Chinese]

Lu Q (1993) Sea ice disaster and its countermeasures of Bohai in China. J. Natur. Disasters, 2(4), 53-59 [in Chinese]

State Oceanic Administration People's Republic of China (SOAPRC) (2011a) Statistical communique of marine economy of China in 2010. State Oceanic Administration People's Republic of China [in Chinese] http://www.soa.gov.cn/soa/hygbml/jjgb/ten/webinfo/2011/03/1299461294174181.htm

SOAPRC (2011b) Statistical communique of maritime hazard of China from 2001-2010. State Oceanic Administration People's Republic of China [in Chinese] http://www.soa.gov.cn/soa/ hygbml/zhgb/ten/webinfo/2011/04/1303019794600094.htm

Whiteman CA (2011) Cold region hazards and risks. WileyBlackwell, Chichester

Xie F, Gu W, Yuan Y and Chen Y (2003) Estimation of sea ice resources in Liaodong Gulf using remote sensing. Resources Sci., 25(3), 17-23 [in Chinese]

Xie F, Gu W, Ha S, Cui W and Chen W (2006) An experimental study on the spectral characteristics of one year-old sea ice in the Bohai Sea, China. Int. J. Remote Sens., 27(14), 3057-3063 (doi: 10.1080/01431160600589153)

Xu G, Kuai M, Zhang E and Jin W (2010) Method and management of holothurian culture during sea ice disaster in winter. China Fisheries, 11, 45-46 [in Chinese]

Xue C, Wang G and Jin S (2004) Review on the culture environment of the marine intertidal shellfish. Ecol. Environ., 13(1), 116-118 [in Chinese]

Yuan S and 6 others (2012) The estimate of sea ice resources quantity in the Bohai Sea based on NOAA/AVHRR data. Acta Oceanol. Sin., 31(1), 33-40 (doi: 10.1007/s13131-012-0173-4)

Zadeh LA (1968) Probability measures of fuzzy events. J. Math. Anal. Appl., 23(2), 421-427

Zhang S and Zhou C (2003) Discussions on the sea ice disasters to the navigation in the Bohai Sea and its mitigation. J. Glaciol. Geocryol., 25(S2), 360-362 [in Chinese] 